\title{
Acceptance of domiciliary theophylline monitoring using dried blood spots
}

\author{
J M RATTENBURY* AND J TSANAKAS $\dagger$ \\ Departments of *Chemical Pathology and †Paediatrics, Children's Hospital, Sheffield
}

SUMMARY Filter paper cards incorporating dried blood spots for the measurement of theophylline concentrations were returned by 62 out of 100 asthmatic children sent kits with instructions for their collection. Analysis of the blood spots showed that $37(61 \%)$ of the children who returned them had less than therapeutic blood theophylline concentrations, in $21(34 \%)$ they were therapeutic, and in three $(5 \%)$ they were potentially toxic. The results indicate that most asthmatic children would comply with requests for home monitoring of theophylline concentrations, and that only one third of children receiving theophylline achieved blood concentrations within the therapeutic range.

Theophylline is widely prescribed for the prophylaxis of bronchospasm in asthmatics but its use is attended by difficulties caused by its narrow therapeutic range, its potential toxicity, and its variable pharmacokinetics. ${ }^{12}$ Prescriptions for theophylline are tailored mainly by the effectiveness of the relief of symptoms and the avoidance of side effects, but the monitoring of blood theophylline concentrations is a desirable part of treatment. Such monitoring can indicate compliance with and tolerance towards the prescribed dose, but requires patients to attend a hospital clinic or family practice for blood collection.

Dried blood spots have been used for the measurement of a number of substances including theophylline,$^{3-7}$ and their stability and convenience permit samples to be posted to the laboratory. Such methods are technically feasible, but their use depends upon the willingness of patients to provide samples. We have therefore examined the response of 100 asthmatic children and their families to a request for dried blood spots for theophylline assays. Analysis of the dried blood spots has provided information about blood theophylline concentrations in asthmatic children from samples collected at home.

\section{Patients and methods}

Patients at the Sheffield Children's Hospital were identified as receiving theophylline from prescriptions dispensed by the hospital pharmacy and from requests for measurement of plasma theophylline concentrations received in the laboratory. One hundred outpatients were recruited into the trial from these sources over a period of six months. Written permission to study their patients was obtained from consultant paediatricians and approval for the trial was given by the hospital ethical committee. Patients' demographic details as well as their addresses, theophylline doses, and preparations taken, were extracted from the clinical records. All patients were asthmatics of varying degrees of severity and duration. Some were also receiving other medication for asthma.

Each patient entered into the trial was sent a kit addressed to 'the parent or guardian of . . . . . . .' that contained: a letter to the parent or guardian explaining the purpose of the trial; instructions for two fingerprick blood samples to be taken four hours after the morning dose of theophylline; a filter paper card to receive the blood spots with spaces for the patient's name, the date and time of sampling and of the last dose of theophylline to be entered; two sterile lancets; a photocopy of a filter paper card showing how correctly taken blood spots should look (figure); and an envelope with a first class stamp on it addressed to the laboratory.

If there was no response one month after sending the kit, a reminder letter was sent with panels for the parents or patients to tick to indicate why the sample had not been sent. The date of receipt of cards in the laboratory was noted and they were stored desiccated at $-20^{\circ} \mathrm{C}$.

Discs $6 \mathrm{~mm}$ in diameter were punched from dried blood spots taken from storage and analysed for theophylline by a method described elsewhere. ${ }^{7}$ 


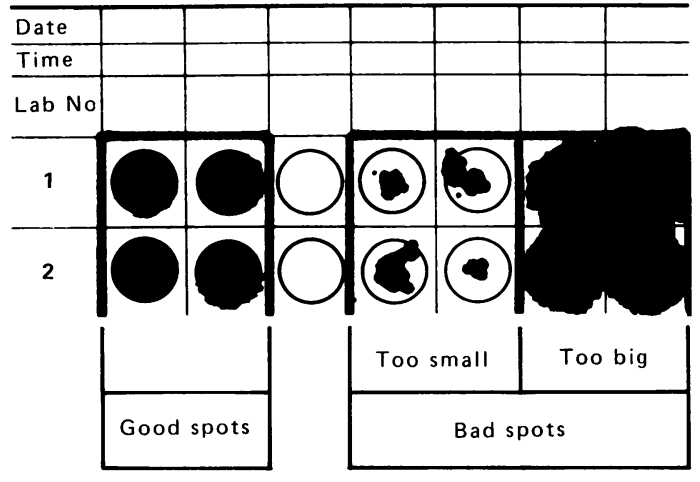

Make sure your blood spots are good ones and fill the circles, or we will not be able to test them

Figure Demonstration card sent out with collection kits showing how correctly taken blood spots should look.

This consists of autoclaving the dried blood spots to fix protein, eluting theophylline with water and measuring it in the eluate by enzyme immunoassay (EMIT). Dried blood spots were considered suitable for analysis if the discs punched from them contained blood spread evenly over the whole of each side. Dried blood spots that did not fulfil these criteria were deemed unsatisfactory, and discs difficult to categorise were classed as doubtful. The batch to batch coefficients of variation of the assay for quality control samples run during the trial were $5.4 \%$ at $5.4 \mathrm{mg} / \mathrm{l}$, and $6.3 \%$ at $18.6 \mathrm{mg} / \mathrm{l}$. The derived therapeutic range of theophylline concentrations by this method is $7-14 \mathrm{mg} / 1 .{ }^{7}$ Plasma theophylline was measured by high performance liquid chromatography ${ }^{8}$ with a therapeutic range of $10-20 \mathrm{mg} / \mathrm{l}$.

\section{Results}

Of the 100 children recruited, 64 were boys and 36 girls with a median age at the time that the kits were distributed of 4 years 1 month (range 14 months to 15 years 9 months) (table). Seventy seven of the children were receiving sustained release theophylline preparations, 67 of the prescriptions being for Slo-phyllin (Lipha Pharmaceuticals Ltd, West Drayton), eight for Theo-Dur (Fisons plc, Loughborough), and two for Phyllocontin (Napp Laborories Ltd, Cambridge). Nine children were receiving the non-sustained release preparation Nuelin (Riker Laboratories, Loughborough) and 14 children had stopped taking theophylline. The mean daily dose of theophylline was $300 \mathrm{mg}$ with a range from 60 to $1350 \mathrm{mg}$ for regimens that varied from one to four doses a day.

Cards incorporating dried blood spots were returned by 62 patients $(62 \%)$. Forty eight $(77 \%)$ of the cards returned had at least two satisfactory dried blood spots, and a further six $(10 \%)$ contained at least one such spot. It became apparent that results from satisfactory and doubtful dried blood spots did not differ significantly and the latter were therefore included in the summarised results. Duplicate results were thus obtained from 56 cards $(90 \%)$ and single results from five $(8 \%)$. Only one card contained wholly unsuitable spots and these results were excluded from analysis. The mean time between kits being sent out and cards returned was 14 days, range 3 to 81 . Reminders were sent to 33 patients who had not returned cards one month after the kits were dispatched, and six completed cards were returned after this.

Sixty $(97 \%)$ of the cards returned had the date of collection of the dried blood spots recorded as requested. These gave a mean time of $2 \cdot 1$ days (range 0 to 9 days) between blood spot collection and receipt by the laboratory. The instructions sent out with the kits required that samples be taken four hours after the morning dose of theophylline and that these times should be recorded. Twenty five $(40 \%)$ of the returned cards showed that this request had been complied with, but in addition three patients indicated that they had collected their

Table Response rates and theophylline concentrations for dried blood spots requested from children at home

\begin{tabular}{lllll}
\hline $\begin{array}{l}\text { Age group } \\
\text { years) }\end{array}$ & $\begin{array}{l}\text { No } \\
\text { in trial }\end{array}$ & $\begin{array}{l}\text { No (\%) of } \\
\text { cards returned }\end{array}$ & $\begin{array}{l}\text { No of results } \\
\text { within the therapeutic } \\
\text { range of } 7-14 \text { mg/l } \\
(\% \text { of } 61 \text { cards returned } \\
\text { with satisfactory spots) }\end{array}$ & $\begin{array}{l}\text { Dried blood spot } \\
\text { theophylline } \\
\text { concentrations } \\
\text { (mean }(\text { SEM) mg/l) }\end{array}$ \\
\hline $1 \cdot 2-3$ & 48 & $25(52 \%)$ & $10(40 \%)$ & $6 \cdot 67(0 \cdot 85)$ \\
$4-6$ & 29 & $17(59 \%)$ & $6(35 \%)$ & $6 \cdot 43(0 \cdot 86)$ \\
$7-15$ & 23 & $20(87 \%)$ & $5(25 \%)$ & $4 \cdot 72(0 \cdot 99)$ \\
\hline Total & 100 & $62(62 \%)$ & $21(34 \%)$ & $5 \cdot 96(0 \cdot 53)$ \\
\hline
\end{tabular}


samples five hours, one patient eight hours, and one patient nine hours after the last dose.

The mean dried blood spot theophylline concentration of the 61 patients whose cards could be analysed satisfactorily was $5.96 \mathrm{mg} / \mathrm{l}$ with a range of 0 to $15.7 \mathrm{mg} / \mathrm{l}$. When concentrations were compared with the therapeutic range of 7 to $14 \mathrm{mg} / \mathrm{l}$ for this method, ${ }^{7} 37$ (61\% of these children) had less than therapeutic concentrations, $21(34 \%)$ had therapeutic concentrations, and three (5\%) had concentrations above the therapeutic range. Of the 38 children who did not return spots, 12 were found subsequently to have discontinued theophylline and six parents informed us that they were unwilling or unable to collect the dried blood spots themselves. During the trial, and independently from it, 43 blood samples (32 outpatient, 11 inpatient) were sent to the laboratory from 38 of the chilren in the study for the measurement of plasma theophylline concentrations. Of these samples, $56 \%$ showed less than therapeutic concentrations, $42 \%$ showed therapeutic concentrations, and $2 \%$ showed concentrations above the therapeutic range for theophylline in plasma (10-20 mg/l).

\section{Discussion}

Various methods for the measurement of theophylline in dried blood spots have been reported ${ }^{3-7}$ but there have been no studies to investigate the acceptance of dried blood spot samples by patients. In the present study 62 of 100 unselected paediatric patients complied with a request to send dried blood spots for theophylline assay. The true response rate, however, was $72 \%$ if the 14 patients who discontinued theophylline during the trial are excluded. This is a favourable response from families approached by letter alone, and may be compared with a response rate of $67 \%$ for a clinic based study of dried blood spot glucose estimations in diabetic children over 7 years of age. ${ }^{9}$ Most of the samples received in the present study were suitable for duplicate analysis and only one returned card was completely unusable. This also compared favourably with the glucose study in which $17 \%$ of returned dried blood spots were unsuitable for analysis.

The proportion of boys to girls in the study and the age distribution were typical of asthmatic patients receiving theophylline in this hospital. The predominance of younger children (table) reflected the use of theophylline as prophylaxis in children too young to use inhalers. Compliance with the request to supply dried blood spots increased with age.

Instructions for collecting the dried blood spots gave no indication of urgency and if the cards come into general use, effort may be required to persuade patients to respond more promptly. On the other hand, the mean time between collection of the blood spots and return of the cards to the laboratory was acceptable at $2 \cdot 1$ days, as theophylline in dried blood spots is stable for at least one month. ${ }^{6}$ Twenty five of the returned cards $(40 \%)$ indicated that the specimen had been collected four hours after the last theophylline dose as requested, and these had a mean (SEM) concentration of $6 \cdot 0(0 \cdot 81) \mathrm{mg} / \mathrm{l}$. The mean concentration for dried blood spots from cards that did not carry this information was not significantly different $(5.93(0.71))$ and this suggests that more patients complied with the required sampling time than those who recorded it on their cards. The proportions of all children who returned dried blood spots and who had theophylline concentrations that were less than therapeutic $(61 \%)$, therapeutic $(34 \%)$, or potentially toxic $(5 \%)$ were similar to those who indicated that the samples were collected four hours after the last dose $(64 \%, 32 \%$, and $4 \%$ respectively), and both groups included fewer in the therapeutic range than the plasma theophylline concentrations requested for routine monitoring.

Studies in adults have shown that up to $70 \%$ of patients may have less than therapeutic concentrations of theophylline, ${ }^{210}$ and in children $98 \%$ of those receiving a non-sustained release theophylline preparation were less than therapeutic. ${ }^{11}$ The proportion of children with therapeutic concentrations decreased with age and did not include any over 11 years old. There was no correlation $(r=0 \cdot 19)$ between doses of theophylline prescribed and dried blood spot concentrations, with no improvement if only results from spots noted to have been collected four hours post dose are analysed. Six children had dried blood spot theophylline concentrations of less than $0.1 \mathrm{mg} / \mathrm{l}$, suggesting that the theophylline prescribed was not being taken.

The results of this study are encouraging with regard to the willingness of paediatric patients and their parents to provide samples for dried blood spot analysis. Patients were only asked to take samples on one occasion and a more prolonged investigation would be required to see whether the response rate changed if regular sampling were requested. Supervision of the sampling arrangements from outpatient clinics might help to maintain compliance. The distribution of theophylline concentrations in the analysed dried blood spots supports previous reports that theophylline prescribing is conservative. It is recognised that the clinical response (such as an improvement in the forced expiratory volume in the first second) to prescribed theophylline is of prime importance, because symptoms may be relieved when circulating concentrations are below the 
therapeutic range. ${ }^{12}$ Nevertheless the availability of a domiciliary monitoring service based on dried blood spot analysis would complement such assessment and give physicians additional confidence to prescribe an appropriate theophylline regimen.

We thank the consultant paediatricians who agreed that children in their care could enter this study, Professor R D G Milner for his encouragement and helpful discussion, Mrs Ruth White for collating information, the Sheffield Asthma Society for financial assistance, and Mrs Angela Gillott for typing the manuscript.

\section{References}

1 Editorial. What therapeutic drugs should be monitored? Lancet 1985;ii:309-10.

2 Woodcock AA, Johnson MA, Geddes DM. Theophylline prescribing, serum concentrations, and toxicity. Lancet 1983;ii: 610-2.

${ }^{3}$ Albani M, Toseland PA. A simple rapid gas chromatographic method for the determination of theophylline in dried whole blood on filter paper cards. Neuropadiatrie 1978;9:97-9.

${ }^{4}$ Brazier JL, Delaye D, Desage M, Bonner A. Simultaneous microdetermination of theophylline, caffeine and phenobarbital in blood collected on filter paper. J Chromatogr 1981;224:439-48.

5 Coombes EJ, Gamlen TR, Batstone GF, Holgate ST. The validation of a fluorimmunoassay for the determination of theophylline concentration in dried blood spots suitable for domiciliary therapeutic drug monitoring. Clin Chim Acta 1984; 136:187-95.

${ }^{6}$ Li PK, Lee JT, Conboy KA, Ellis EF. Fluorescence polarization immunoassay for theophylline modified for use with dried blood spots on filter paper. Clin Chem 1986;32:552-5.

7 Rattenbury JM, Taylor T. Measurement of theophylline in dried blood spots by spectrophotometric enzyme immunoassay. Ann Clin Biochem 1988; 25: 650-3.

${ }^{8}$ Nelson JW, Cordry AL, Aron CG, Bartell RA. Simplified micro-scale procedure for preparing samples for theophylline determination by liquid chromatography. Clin Chem 1977;23: 124-6.

9 Baumer JE, Edelsten AD, Howlett BC, Owens C, Pennock CA, Savage DCL. Impact of home blood glucose monitoring on childhood diabetes. Arch Dis Child 1982;57:195-9.

${ }^{10}$ Brodie MJ, McIntosh ME, Hallworth M. Therapeutic drug monitoring - the need for audit. Scott Med J 1985;30:75-82.

1 Sublett JL, Pollard SJ, Kadlec GJ, Karibo JM. Non-compliance in asthmatic children: a study of theophylline levels in a pediatric emergency room population. Ann Allergy 1979;43: 95-7.

12 Maselli R, Casal GL, Ellis EF. Pharmacologic effects of intravenously administered aminophylline in asthmatic children. J Pediatr 1970;76:777-82.

Correspondence to Dr J M Rattenbury, Department of Chemical Pathology, Children's Hospital, Western Bank, Sheffield S10 2TH.

Accepted 5 July 1988 